\title{
Vertical growth phase and positive sentinel node in thin melanoma
}

R.S. Oliveira Filho ${ }^{1}$,

L.M. Ferreira ${ }^{1}$, L.J. Biasi ${ }^{1}$, M.M.S.S. Enokihara ${ }^{2}$, G.R. Paiva ${ }^{1}$ and J. Wagner ${ }^{3}$

\author{
${ }^{1}$ Disciplina de Cirurgia Plástica, Departamento de Cirurgia, and \\ 2Departamento de Patologia, Escola Paulista de Medicina, \\ Universidade Federal de São Paulo, São Paulo, SP, Brasil \\ ${ }^{3}$ Serviço de Medicina Nuclear, Hospital Israelita Albert Einstein, \\ São Paulo, SP, Brasil
}

\section{Correspondence \\ R.S. Oliveira Filho \\ R. Carlos Millan, 37 \\ 01456-030 São Paulo, SP \\ Brasil \\ Fax: +55-11-3032-0763 \\ E-mail: renato.dcir@epm.br}

Research partially supported by FAPESP (No. 97/02516-0).

Received February 18, 2002 Accepted October 31, 2002

\begin{abstract}
Sentinel node (SN) status is the most important prognostic factor for localized melanoma. Usually, patients with Breslow thickness of less than $1.0 \mathrm{~mm}$ are not included in SN protocols. However, the literature presents a rate ranging from 3 to $7 \%$ of nodal recurrence in thin melanoma. Ulceration, regression and high mitotic rate have been considered to be indications for an SN biopsy. The metastatic potential of the vertical growth phase is uncertain. To correlate pathological features in thin melanoma with SN metastasis, we reviewed 358 patients submitted to SN biopsy. Seventy-seven patients with lesions of $1 \mathrm{~mm}$ or smaller were included in the study group. Histological evaluation of the primary tumor included thickness, Clark level, mitotic rate, ulceration, regression, and growth phase. Lymphoscintigraphy was performed on all patients. Lymphatic mapping and gamma probe detection were both used for SN biopsy. Histological examination of SN consisted of hematoxylin-eosin and immunohistochemical staining. Median follow-up was 37 months. Six patients had micrometastases. Statistical analysis by the Fisher test showed that ulceration $(P=0.019)$, high mitotic rate $(P=0.008)$ and vertical growth phase $(\mathrm{P}=0.002)$ were positively correlated with micrometastases. If other studies confirm these results, more melanoma patients must be submitted to SN biopsy.
\end{abstract}

The overall incidence of melanoma has been rising all over the world. The proportion of thin melanoma has increased as compared to more deeply infiltrating lesions (13 ). Sentinel node ( $\mathrm{SN}$ ) biopsy proved to be an accurate staging procedure of regional nodal status with minimal morbidity and SN status is the most important prognostic factor for localized melanoma $(4,5)$.

What does thin metastasizing melanoma have that confers this phenotype? This is still an unsolved question. The latest proposed
Key words

- Thin melanoma

- Sentinel node

- Lymphoscintigraphy

- Immunohistochemistry

- Micrometastasis change of the tumor-node-metastasis (TNM) cutaneous melanoma classification includes the presence or absence of ulceration and Clark level in category "T" (6). Patients with thin primary melanoma $(\leq 1 \mathrm{~mm})$ without ulceration and with a Clark level of less than IV are expected to have an excellent prognosis (7). However, some of these patients with low risk disease develop recurrence and death. The literature presents a rate of nodal recurrence ranging from 3 to $7 \%$ in thin melanoma patients (8-11). Other pathologi- 
cal features such as ulceration, mitotic rate, regression and vertical growth phase are supposed to play an important role in the determination of recurrence risk in thin melanoma and have been considered as indicators for an SN biopsy $(12,13)$.

The early steps in the development and progression of malignant melanoma include proliferation of transformed epidermal melanocytes and their subsequent invasion of the papillary dermis (radial growth phase). This can be followed by the vertical growth phase, a step with metastatic capability (14). The identification of parameters that might predict progression and survival is mandatory for thin melanoma (1).

In the SN biopsy protocol of our institutions we have included melanoma patients with thin melanoma. Some of them have recurred. To address why these patients have recurred we analyzed the pathological features of their primary melanoma, including vertical growth phase.

Between June 1997 and January 2002, 358 patients with clinically localized cutaneous melanoma underwent a successful SN biopsy, according to protocols approved by the Ethics Committee of Escola Paulista de Medicina, UNIFESP, and Hospital Israelita Albert Einstein. Among them, 77 had lesions $1 \mathrm{~mm}$ or smaller and formed our study sample. Informed consent was obtained from all patients. Clinically node-negative melanoma patients were enrolled into our protocol if Breslow thickness was $1.0 \mathrm{~mm}$ or more and those with thickness of less than $1.0 \mathrm{~mm}$ with ulceration, more than 5 mitoses $/ \mathrm{mm}^{2}$, regression or Clark level IV or V were also included. The histological evaluation of the primary lesion included tumor thickness, Clark level, mitotic rate, ulceration, regression, vascular invasion, tumor-infiltrating lymphocytes, and growth phase. The presence of vertical growth phase was determined as described by Clark et al. (12).

Lymphoscintigraphy was performed in all patients. A quantity of $1 \mathrm{mCi}\left(\mathrm{Tc}^{99 \mathrm{~m}_{-}}\right.$ dextran 500) in a $1-\mathrm{ml}$ volume of $0.9 \%$ normal saline was injected intradermally in equal parts into four quadrants around the biopsy scar or primary tumor. The images were obtained with a gamma camera with a highresolution collimator (Starcam 4000600 $\mathrm{X} / \mathrm{RT}$ ). The projection of the $\mathrm{SN}$ was marked on the overlying skin with indelible ink. Surgery was performed 2 to $24 \mathrm{~h}$ after lymphoscintigraphy. For the first 43 patients the SN biopsy was based only on preoperative lymphoscintigraphy and vital blue dye mapping (Patent Blue V, Laboratoire Guerbet, Aulnay-sous Bois, France).

Intraoperative gamma probe detection (Neoprobe 1500, Columbus, OH, USA) was added to the protocol for the remaining 315 patients. The node was considered to be an $\mathrm{SN}$ if it was blue and/or showed counts fivefold higher than background in vivo or tenfold higher ex vivo. After the SN was excised, the surgeon examined the operative field with the probe. If there was $10 \%$ or more capitation of the $\mathrm{SN}$, the surgeon looked for another node. The SN was trimmed of excess fat and sectioned by the surgeon into four fragments in the operating room. Two noncontiguous fragments were sent to pathology and the others were submitted to molecular biology examination (RT-PCR for tyrosinase mRNA). The histological examination consisted of hematoxylin-eosin staining and immunohistochemical markers for S100 and HMB45. When hematoxylin-eosin and/or immunohistochemical study showed the presence of micrometastases in the $\mathrm{SN}$, complete lymphadenectomy was performed. Patients with a negative $\mathrm{SN}$ were just followed up. The median follow-up was 37 months. Fisher's exact test was applied to determine the association between pathological features and the occurrence of a positive SN.

The primary site was localized on the head and neck, trunk and extremities in 14, 27 and 36 patients, respectively. The median age of the 77 thin melanoma patients was 52.5 years. There were 34 male and 43 fe- 
male patients. Lymphoscintigraphy successfully identified the draining lymphatic basin and SN in all 77 patients. On the basis of vital dye and/or intraoperative gamma detection, $97.8 \%$ of the $\mathrm{SN}$ identified by lymphoscintigraphy were found and excised. Metastatic spread was diagnosed in six patients. We focused on these six patients comparing their pathological features with those of 71 thin melanoma patients who did not present micrometastases in the SN. Statistical analysis by the Fisher test showed that ulceration $(\mathrm{P}=0.019)$, high mitotic rate $(\mathrm{P}=$ $0.008)$ and vertical growth phase $(\mathrm{P}=0.002)$ were positively correlated with micrometastases (Table 1). All six patients with micrometastases showed the vertical growth phase in the primary lesion, five of them had more than 5 mitoses $/ \mathrm{mm}^{2}$, four of them had ulceration, and three had regression. Additional characteristics of these six thin melanoma patients who presented SN metastases are shown in Table 2.

The rate of occurrence of nodal metastases in our group of patients with thin melanoma (Breslow thickness $1 \mathrm{~mm}$ or smaller) was $7.8 \%(6 / 77)$. All six patients showed the vertical growth phase in their primary tumor. These six patients underwent complete lymphadenectomy and none of them showed another positive lymph node.

Previous publications have emphasized that tumors with vertical growth phase need to be considered as high risk for regional node metastasis $(14,15)$. There is evidence that thin melanoma with radial growth phase does not metastasize $(16,17)$. Our results support that vertical growth phase, high mitotic rate and ulceration are indications for SN biopsy. If other studies, with multivariant analysis, confirm our results, more melanoma patients must be submitted to SN biopsy $(1,18)$.

Table 1. Sentinel node micrometastasis and pathological features in 77 thin melanoma patients $(\leq 1.0$ $\mathrm{mm})$.

\begin{tabular}{lccc}
\hline & \multicolumn{2}{c}{ Micrometastasis } & \multirow{2}{*}{$P^{*}$} \\
\cline { 2 - 3 } & No $(\mathrm{N}=71)$ & Yes (N =6) & \\
\hline Clark & & & 0.376 \\
III & 35 & 2 & \\
IV & 36 & 4 & \\
Ulceration & & & 0.019 \\
Yes & 13 & 4 & \\
No & 58 & 2 & \\
Regression & & & 0.084 \\
Yes & 12 & 3 & \\
No & 59 & 3 & \\
$>5$ mitoses/mm 2 & & & 0.008 \\
Yes & 18 & 5 & \\
No & 53 & 1 & \\
VGP & & & 0.002 \\
Yes & 22 & 6 & \\
No & 49 & 0 & \\
\hline
\end{tabular}

VGP = vertical growth phase. ${ }^{*}$ Fisher test.

\begin{tabular}{|c|c|c|c|c|c|c|}
\hline Patient & 1 & 2 & 3 & 4 & 5 & 6 \\
\hline Sex & $\mathrm{F}$ & $\mathrm{F}$ & $\mathrm{F}$ & M & M & $\mathrm{F}$ \\
\hline Age (years) & 57 & 38 & 74 & 42 & 48 & 56 \\
\hline Site & Trunk & Trunk & Extremity & Extremity & Trunk & Trunk \\
\hline Type & Nodular & SSM & SSM & SSM & Nodular & SSM \\
\hline Breslow & 0.8 & 0.5 & 0.6 & 0.4 & 0.9 & 0.8 \\
\hline Clark & IV & III & IV & III & IV & IV \\
\hline Ulceration & No & Yes & Yes & Yes & No & Yes \\
\hline Regression & Yes & Yes & No & No & Yes & No \\
\hline$>5$ mitoses $/ \mathrm{mm}^{2}$ & Yes & Yes & No & Yes & Yes & Yes \\
\hline VGP & Yes & Yes & Yes & Yes & Yes & Yes \\
\hline
\end{tabular}

$\mathrm{SSM}=$ superficial spreading melanoma; $\mathrm{VGP}=$ vertical growth phase; $\mathrm{F}=$ female; $\mathrm{M}=$ male . 


\section{References}

1. Massi D, Franchi A, Borgognoni L, Reali UM \& Santucci M (1999). Thin cutaneous malignant melanoma $(\leq 1.5 \mathrm{~mm})$ : identification of risk factors indicative of progression. Cancer, 85: 1067-1076.

2. Lopes MM, Oliveira Filho RS, Teshiroqui E, Calvis LA \& Tovo LF (1997). Melanoma primário múltiplo. Anais Brasileiros de Dermatologia, 71: 677-681

3. Brozena SJ, Fenske NH \& Perez OR (1993). Epidemiology of malignant melanoma, worldwide incidence and etiologic factors. Seminars in Surgical Oncology, 9: 165-173.

4. Morton DL, Thompson JF, Essner R, Elashoff R, Stern SL, Nieweg OE, Roses DF, Karakousis CP, Mozzillo N, Reintgen D, Wang HJ, Glass EC \& Cochran AJ (1999). Validation of the accuracy of intraoperative lymphatic mapping and sentinel lymphadenectomy for earlystage melanoma. Annals of Surgery, 230: 453-465.

5. Oliveira Filho RS, Enokihara M, Barbieri A, Santos IO \& Ferreira LM (2000). Is intra-operative gamma-probe detection really necessary for inguinal lymph node biopsy? São Paulo Medical Journal, 118: 165-168.

6. Balch CM, Buzaid AC, Soong SJ, Atkins MB, Cascinelli N, Coit DG, Fleming ID, Gershenwald JE, Houghton Jr A, Kirkwood JM, McMasters KM, Mihm MF, Morton DL, Reintgen DS, Ross MI, Sober A, Thompson JA \& Thompson JF (2001). Final version of the American Joint Committee on Cancer staging system for cutaneous melanoma. Journal of Clinical Oncology, 19: 3635-3648.

7. Kelly JW, Sagebiel RW, Clyman S \& Blois MS (1985). Thin level IV malignant melanoma: a subset in which level is the major prognostic indicator. Annals of Surgery, 202: 98-103.

8. Naruns PL, Nizze JA, Cochran AJ, Lee MB \& Morton DL (1986), Recurrence potential of thin primary melanomas. Cancer, 57: 545548.

9. Slingluff Jr CL, Vollmer RT, Reintgen DS \& Seigler HF (1988). Lethal "thin" malignant melanoma. Annals of Surgery, 208: 150-161.
10. Woods JE, Soule EH \& Creagan ET (1983). Metastasis and death in patients with thin melanoma (less than $0.76 \mathrm{~mm}$ ). Annals of Surgery, 198: 63-64.

11. Shaw HM, McCarthy WH, McCarthy SW \& Milton GW (1987). Thin malignant melanomas and recurrence potential. Archives of Surgery, 122: 1147-1150.

12. Clark Jr WH, Elder DE, Guerry 4th D, Braitman LE, Trock BJ, Schultz D, Synnestvedt M \& Halpern AC (1989). Model predicting survival in stage I melanoma based on tumor progression. Journal of the National Cancer Institute, 81: 1893-1904.

13. Szymik B \& Woosley J (1993). Further validation of the prognostic model for stage I malignant melanoma based on tumor progression. Journal of Cutaneous Pathology, 20: 50-53.

14. Bedrosian I, Faries MB, Guerry 4th D, Elenitsas R, Schuchter L, Mick R, Spitz FR, Bucky LP, Alavi A, Elder DE, Fraker DL \& Czerniecki BJ (2000). Incidence of sentinel node metastasis in patients with thin primary melanoma $(\leq 1 \mathrm{~mm})$ with vertical growth phase. Annals of Surgical Oncology, 7: 262-267.

15. Thompson JF \& Shaw HM (2000). Sentinel node metastasis from thin melanomas with vertical growth phase. Annals of Surgical Oncology, 7: 251-252.

16. Guerry 4th D, Synnestvedt M, Elder DE \& Schultz D (1993). Lessons from tumor progression: the invasive radial growth phase of melanoma is common, incapable of metastasis, and indolent. Journal of Investigative Dermatology, 100: 342S-345S.

17. Clark Jr WH, Elder DE, Guerry 4th D, Epstein MN, Greene MH \& Van Horn M (1984). A study of tumor progression: the precursor lesions of superficial spreading and nodular melanoma. Human Pathology, 15: $1147-1165$.

18. Barnhill RL, Fine JA, Roush GC \& Berwick M (1996). Predicting fiveyear outcome for patients with cutaneous melanoma in a population based study. Cancer, 78: 427-432. 